\title{
SARS-CoV-2: generalidades bioquímicas y métodos de diagnóstico
}

SARS-CoV-2: biochemical aspects and diagnostic methods

Brigitte Ofelia Peña López ${ }^{1}$, Bladimiro Rincón Orozco² ${ }^{2}$ John Jairo Castillo León ${ }^{3}$

\section{Resumen}

El 31 de diciembre de 2019 la comisión municipal de salud de Wuhan (provincia de Hubei, China) informa sobre un inusitado brote de casos de neumonía en la ciudad. Posteriormente se determina que se trata de un nuevo coronavirus designado inicialmente como 2019-nCoV y posteriormente, SARS-CoV-2. El SARS-CoV-2 infecta y se replica en los neumocitos y macrófagos del sistema respiratorio específicamente en el parénquima pulmonar en donde reside el receptor celular ACE-2. Esta revisión describe aspectos relacionados con la transmisión, prevención, generalidades bioquímicas del SARS-CoV-2 y métodos diagnósticos del COVID-19. Inicialmente se describe la forma de transmisión del virus y algunas recomendaciones generales para su prevención. Posteriormente, se hace una descripción detallada de los aspectos bioquímicos del SARS-CoV-2, su ciclo infeccioso y la estructura de la proteína $S$, la cual está involucrada con el proceso de ingreso del virus a la célula. Finalmente, se describen los métodos y pruebas de laboratorio para el diagnóstico del COVID-19.

Palabras claves: SARS-CoV-2, COVID-19, Glicoproteína de la Espiga del Coronavirus, Coronavirus, Transmisión, Diagnóstico.

\footnotetext{
1. Microbióloga y bioanalista, Escuela de Microbiología, Universidad Industrial de Santander. ORCID: https://orcid.org/0000-0001-5026-1880

2. Ph.D. Profesor Titular, Escuela de Microbiología, Universidad Industrial de Santander. ORCID: https://orcid.org/0000-0001-5323-0422

3. Ph.D. Profesor Asociado, Escuela de Química, Universidad Industrial de Santander. ORCID: https://orcid.org/0000-0002-6751-2305

Correo electrónico de correspondencia: jcasleon@uis.edu.co
}

https://doi.org/10.22490/24629448.4183 


\section{Abstract}

On December 31, 2019, Wuhan Municipal Health Commission (Hubei Province, China) reports on an unusual outbreak of pneumonia cases in the city. Subsequently it is determined that it is a new coronavirus initially designated as 2019-nCoV and later, SARS-CoV-2. SARS-CoV-2 infects and replicates in pneumocytes and macrophages of the respiratory system specifically in the lung parenchyma where the ACE-2 cell receptor resides. This review describes aspects related to the transmission, prevention, biochemical generalities of SARS-CoV-2 and diagnostic methods of COVID-19. Initially, it describes the form of virus transmission and general recommendations for its prevention. Subsequently, a detailed description is made of the biochemical aspects of SARS-CoV-2, its infectious cycle and the structure of protein $S$, which is involved in the process of entry of the virus into the cell. Finally, the methods and laboratory tests for the diagnosis of COVID-19 are described.

Keywords: SARS-CoV-2, COVID-19, Spike Glycoprotein, Coronavirus Transmission, Diagnosis.

\section{Introducción}

En una línea de tiempo que llega hasta la actualidad, una epidemia de casos de infecciones respiratorias bajas detectadas en Wuhan se informó a la oficina de la OMS en China, en diciembre de 2.019 (1). El Centro Chino para el Control y Prevención de Enfermedades (CDC) y los CDC locales organizaron un programa intensivo de investigación de brotes (2).

La etiología de esta enfermedad, denominada enfermedad por coronavirus 2019 (COVID-19), se atribuye a un nuevo virus perteneciente a la familia del coronavirus (CoV) llamado SARS-CoV-2 (3). Este nuevo virus es altamente contagioso y se ha expandido rápidamente por todo el mundo. El brote fue declarado por la Organi- zación Mundial de la Salud (OMS) como Emergencia de Salud Pública de Preocupación Internacional (4). El 11 de marzo, cuando el número de casos de COVID-19 fuera de China aumentó 13 veces y el número de países involucrados se triplicó con más de 118.000 casos en 114 países y más de 4.000 muertes, la OMS declaró al COVID-19 una pandemia (5).

Según la OMS, las enfermedades virales continúan surgiendo y representan un problema grave para la salud pública. En los últimos veinte ańos, se han producido dos epidemias adicionales causadas por $\mathrm{CoV}$ : el coronavirus del síndrome respiratorio agudo severo (SARS-CoV) en 2002 que provocó una epidemia a gran escala que comenzó en China e involucró a dos docenas de países con aproximadamente 8.000 
casos y 800 muertes; y el coronavirus del síndrome respiratorio del Medio Oriente (MERS-CoV) en 2012 que comenzó en Arabia Saudita y ha causado aproximadamente 2.500 casos y 800 muertes y todavía causa casos esporádicos $(6,7)$.

Los CoV se han convertido en los principales patógenos de brotes emergentes de enfermedades respiratorias $(8,9)$. Son virus de ARN monocatenarios de polaridad positiva, pueden aislarse en diferentes especies animales y hacer salto de especie, causando enfermedades en humanos que van desde el resfriado común hasta enfermedades más graves como el MERS y el SARS $(10,11)$. Estos últimos virus probablemente se originaron en murciélagos y luego se trasladaron a otros mamíferos: la civeta de palma del Himalaya para SARS-CoV y el camello dromedario para MERS-CoV, antes de saltar a los humanos (12-14). La dinámica del SARS-Cov-2 se desconoce actualmente, pero se especula que también tiene un origen animal.

Los gobiernos mundiales trabajan para establecer contramedidas para detener posibles efectos devastadores de esta pandemia. Las organizaciones de salud coordinan los flujos de información y emiten directivas y directrices para mitigar mejor el impacto de la amenaza. Al mismo tiempo, los científicos de todo el mundo trabajan incansablemente, y la información sobre los mecanismos de transmisión, el espectro clínico de la enfermedad, los nuevos diagnósticos y las estrategias preventivas y terapéuticas se están desarrollando rápidamente (15). Quedan muchas incertidumbres con respecto a la interacción virus-huésped y a la evolución de la epidemia, con referencia específica a los momentos en que la epidemia alcanzará su punto máximo.

Por el momento, las estrategias terapéuticas para tratar la infección son solo de apoyo, y la prevención dirigida a reducir la transmisión en la comunidad es nuestra mejor arma (16). Las medidas agresivas de aislamiento en China han llevado a una reducción progresiva de casos en los últimos días. En Italia, en regiones geográficas del norte, inicialmente, y posteriormente en toda la península, así como en España las autoridades políticas y sanitarias están haciendo esfuerzos increíbles para contener un tsunami que desplome los sistemas hospitalarios y la economía de estos países $(17,18)$.

Desde su aparición en diciembre de 2019 y hasta la fecha se han registrado aproximadamente 12.000 .000 de personas infectadas en el mundo con una tasa de mortalidad de $7 \%$, y se espera que el número de casos de pacientes infectados aumente exponencialmente (19). En Colombia, el número de casos ya supera los 120.000 infectados, desde la aparición del primer caso a inicios de marzo, con más de 4200 muertes a la fecha (20).

Esta revisión describe los aspectos más importantes de SARS-CoV-2 desde el punto de vista bioquímico-estructural y presen- 
ta los métodos de detección y diagnóstico aprobados por la FDA hasta el mes de abril.

\section{Transmisión}

Los individuos sintomáticos son la fuente más frecuente de propagación del SARSCoV-2 (21). La posibilidad de transmisión antes de que aparezcan los síntomas parece ser poco frecuente, aunque no hay datos contundentes para excluirla (22). Además, es posible que las personas asintomáticas transmitan el virus (23). Estos datos sugieren que el aislamiento es la mejor manera de contener esta epidemia.

La transmisión se produce a través de gotitas respiratorias por toser y estornudar. La transmisión por aerosoles también es posible en caso de exposición prolongada a concentraciones elevadas de aerosoles en espacios cerrados $(24,25)$. Se sugiere que otras vías de transmisión incluyen la vía fecal-oral y la superficie ocular $(26,27)$. El análisis de los datos relacionados con la propagación del SARS-CoV-2 en China parece indicar que cerca que el contacto entre individuos es necesario. La propagación inicial, de hecho, se limita principalmente a miembros de la familia, profesionales de la salud y otros contactos cercanos (24).

Según los datos de los primeros casos en Wuhan y las investigaciones realizadas por el CDC de China y los CDC locales, el tiempo de incubación podría ser general- mente de 3 a 7 días y prolongarse hasta 2 semanas, ya que el tiempo más largo desde la infección hasta los síntomas fue de 12.5 días (95\% IC, 9,2 a 18) $(25,28)$. Estos datos también han mostrado que esta nueva epidemia se duplicó aproximadamente cada siete días, mientras que el número básico de reproducción (R0) es 2,68 (29).

\section{Prevención}

Las medidas preventivas son la estrategia actual para limitar la propagación de casos. Debido a que una epidemia aumentará mientras R0 sea mayor que 1 , las medidas de control deben enfocarse en reducir el valor a menos de 1 .

Las estrategias preventivas se centran en el aislamiento de los pacientes y el control cuidadoso de la infección para mantener el $\mathrm{R}$ igual a 0 , incluidas las medidas apropiadas que deben adoptarse durante el diagnóstico y la prestación de atención clínica a un paciente infectado. Por ejemplo, las gotas, el contacto y las precauciones en el aire en espacios cerrados deben manejar con extremo cuidado durante la recolección de muestras, y debe evitarse la inducción de esputo.

La OMS ha emitido las siguientes recomendaciones generales $(16,30)$ :

a) Evite el contacto cercano con sujetos que padecen infecciones respiratorias agudas. 
b) Lávese las manos con frecuencia, especialmente después del contacto con personas infectadas o su entorno.

c) Evite el contacto sin protección con animales de granja o animales salvajes.

d) Las personas con síntomas de infección aguda de las vías respiratorias deben mantenerse a distancia, cubrirse la boca al toser o estornudar con pańuelos desechables o ropa y lavarse las manos.

e) Fortalecer, en particular, en los departamentos de medicina de emergencia, la aplicación de medidas estrictas de higiene para la prevención y el control de infecciones.

f) Las personas inmunocomprometidas deben evitar las reuniones públicas.

g) La estrategia más importante para los poblados es lavarse las manos con frecuencia y usar desinfectante de manos portátil y evitar el contacto con la cara y la boca después de interactuar con un entorno posiblemente contaminado.

Los trabajadores de la salud que atienden a personas infectadas deben utilizar precauciones de contacto y en el aire para incluir elementos de protección personal como máscaras N95 FFP3, protección para los ojos, batas y guantes para evitar la transmisión del patógeno (31).

\section{Estructura de SARS-CoV-2}

El SARS-CoV-2, conocido así por las espículas presentes en su cápside que forman una especie de corona alrededor de su superficie, es un virus de ARN monocatenario y polaridad positiva de entre 26 y 32 kilobases de longitud, es un virus envuelto y con una nucleocápside de simetría helicoidal, perteneciente a la familia Coronoviridae $(32,33)$. Actualmente, se conocen 4 géneros derivados de la familia principal: alfa-coronavirus, beta-coronavirus, gamma-coronavirus y delta-coronavirus. Se sabe que los géneros alfa y beta-CoV pueden infectar humanos mientras los otros dos géneros sólo infectan aves (10).

Las proteínas de SARS-CoV-2 incluyen proteínas tipo espícula (S), envoltura de membrana (E) y nucleocápside (N) (34). Particularmente, en el SARS-CoV-2, el reconocimiento por parte del receptor de la célula hospedadora se lleva a cabo vía endosoma mediante un dominio de unión que dirige la adherencia del virus al receptor celular, la enzima convertidora de angiotensina 2 (ECA-2) (35). La figura 1, muestra una ilustración de la estructura del SARSCoV-2 y el reconocimiento por parte del receptor viral ECA-2 presente en la superficie de la célula hospedadora. 
Figura 1. Esquema de la estructura de SARS-CoV-2 en su interacción con el receptor ECA-2 de la célula hospedadora.

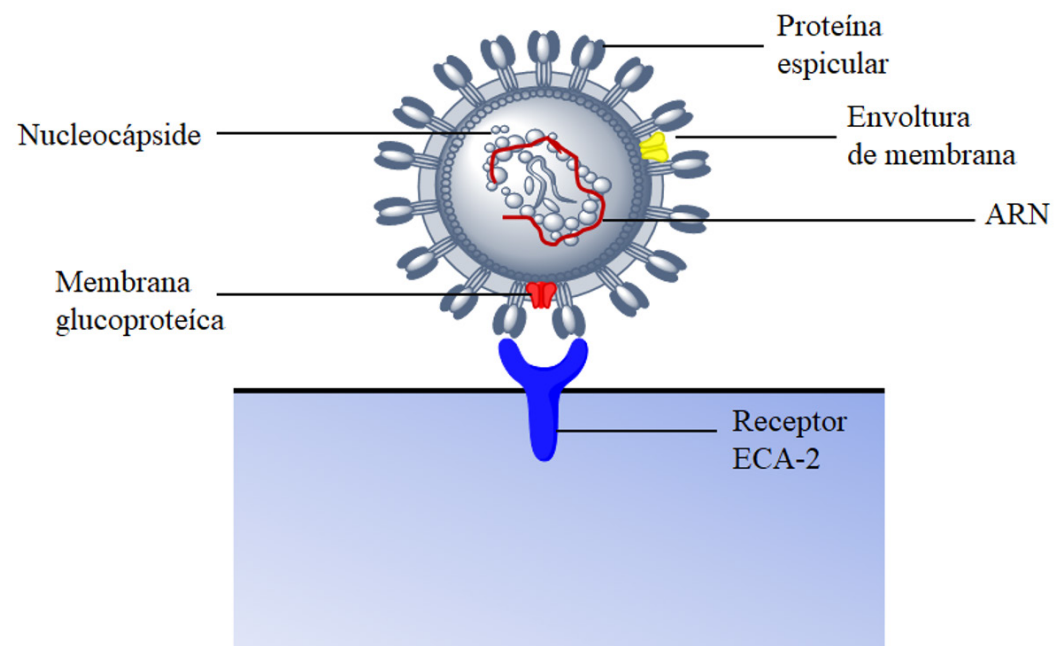

Fuente: Autores.

\section{Ciclo infeccioso de SARS-CoV-2}

El ciclo infeccioso de SARS-CoV-2 inicia con la entrada endosomal del virus a la célula hospedadora mediante la interacción del dominio $S 1$ de la proteína $S$ con receptores ECA-2 presentes principalmente en neumocitos y enterocitos del sistema respi- ratorio (36). Una vez ingresa el virus pierde su envoltura y el genoma viral se libera en el citoplasma traduciéndose en poliproteínas virales de replicasa pp1a y $1 \mathrm{ab}$, que luego se dividen en pequeños productos mediante proteinasas virales, como se observa en la figura 2 (37).

Figura 2. Esquema ilustrativo del ciclo infeccioso de SARS-CoV-2.

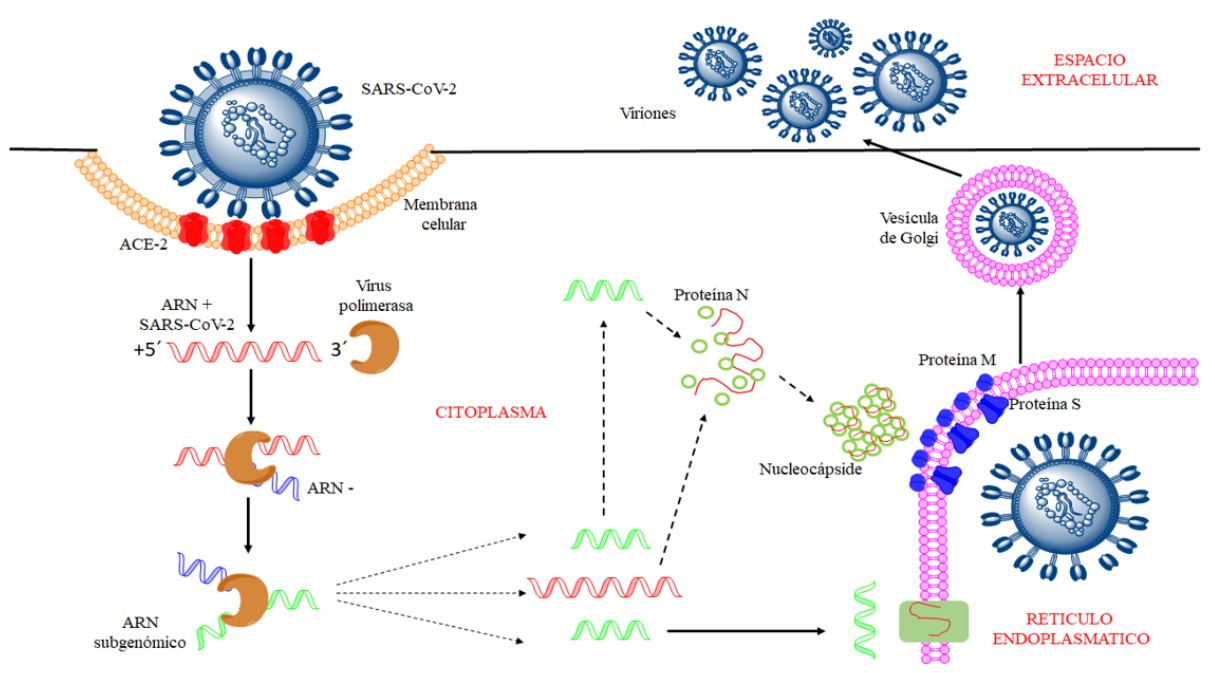

Fuente: Autores. 
El genoma de ARN de SARS-CoV-2 presenta una estructura metilada en el extremo 5' y una cola poliadenilada en el extremo 3'. Esta particularidad hace que al ARN se le adhieran los ribosomas citoplasmáticos para el proceso de traducción. SARS-CoV-2 presenta una proteína replicasa codificada en su genoma, que le permite producir nuevas copias de su ARN (38). Al igual que otros virus de la misma familia del SARS-CoV-2 esta replicasa es la primera proteína que se sintetiza ya que una vez que el gen que codifica la replicasa es traducido, el proceso se detiene por un codón de parada. Las nucleocápsides virales se ensamblan a partir del ARN genómico y la proteína $\mathrm{N}$ viral presente en el citoplasma, para ello utilizan una proteasa denominada 3CLpro25 que corta la poliproteína seguido de la gemación en el lumen del compartimiento intermedio Golgi-retículo endoplasmático. Finalmente, los viriones son liberados de la célula infectada por medio de exocitosis (39).

\section{Estructura de la proteína $S$}

La glicoproteína $S$ es una proteína de membrana integral homo-trimérica tipo I, similar a las glicoproteínas: 160 de VIH (Env), hemaglutinina de la influenza (HA) y a la glicoproteína viral del Ébola $(35,40)$. Está organizada en tres dominios: un dominio extracelular (EC), un dominio de anclaje transmembranal y un dominio tipo cola intracelular. El dominio EC contiene dos subdominios necesarios para el proceso de reconocimiento por parte de la célula hospedadora (S1) y fusión de la membrana (S2). El S1 presenta dos dominios independientes, un dominio N-terminal (S1-NTD) y un dominio de unión al receptor (RBD) (figura 3a), el cual desempeña un papel clave en los procesos de unión y reconocimiento. Durante el proceso de fusión hospedador-virus, la proteína $S$ es cortada en el límite de los subdominios S1/S2 por las proteasas de la célula hospedadora, liberando un péptido de fusión el cual es indispensable para la entrada del virus (41).

Figura 2. Esquema coloreado por dominios de la estructura primaria de la proteína S de SARS-CoV-2. RBD, dominio de unión al receptor; SS, secuencia de las señales; S2', sitio de escisión de proteasas; FP, péptido de fusión; HR1, repetición heptad 1; CH, hélice central; CD, dominio conector; HR2, repetición heptad 2; TM; dominio transmembranal; CT, cola citoplásmica. Las flechas indican los sitios de acción de las proteasas.

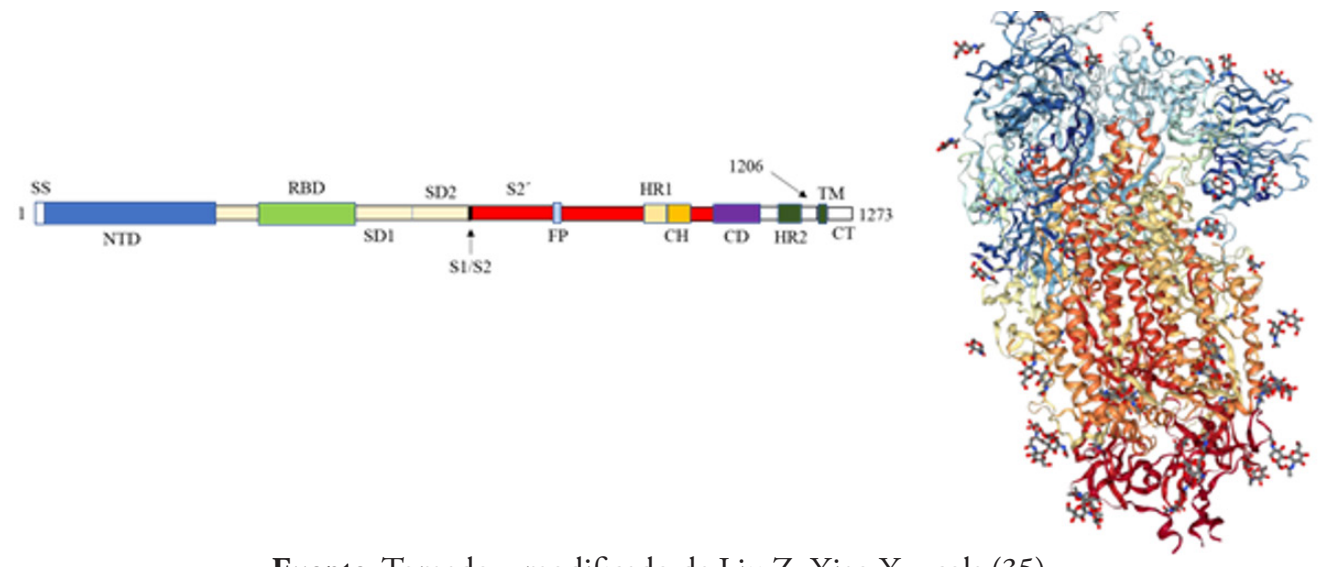

Fuente: Tomado y modificado de Liu Z, Xiao X y cols (35). 
Actualmente se sabe que la proteína $S$ es clave para el desarrollo de vacunas, tratamientos y métodos de diagnóstico (42). Recientemente, Wrapp y cols. elucidaron la estructura cuaternaria de la proteína $S$ en la conformación de prefusión mediante criomicroscopía electrónica de alta resolución, técnica de microscopía electrónica, a temperaturas criogénicas, que permite observar estados conformacionales nativos de proteínas a resolución atómica (43). El estado conformacional predominante del trímero $S$ tiene uno de los tres dominios de unión al receptor (DUR) rotados en una conformación accesible al receptor, como se puede observar en la figura 3.

Diferentes estudios han demostrado la interacción de diferentes tipos de $\mathrm{CoV}$ que comparten la misma afinidad por la ECA2 de las células hospedadoras. En el año $2.003 \mathrm{Li}$ y cols. identificaron una ECA de células Vero E6 infectadas con SARS-CoV que se enlazó eficientemente al dominio $S 1$ de la proteína $S$ del SARS-CoV. Además, se encontró que la enzima ECA-2 en su forma soluble no se enlaza a los receptores presente en células infectadas con VIH (44). Más adelante, precisamente en el ańo 2.020 Hoffman y cols. demostraron que el nuevo SARS-CoV-2 reconoció el receptor ECA-2 por medio de la proteasa celular TMPRSS2 (proteína transmembranal serina 2) (45). Mediante experimentos de resonancia de plasmón superficial (SPR) Wrapp y cols, estudiaron la interacción ECA-2 con la proteína $S$ caracterizada con una constante de afinidad (KD) de $1.42 \mathrm{nM}(43)$.
Es importante recalcar que no únicamente la ECA-2 es el único sitio de recepción identificado hasta ahora para el ingreso de SARS-CoV-2 a la célula hospedadora. Mediante estudios de docking molecular se sabe que probablemente son 4 los sitios que utiliza la proteína $S$ para unirse a una proteína chaperona del retículo endoplasmático conocida como GRP78 para lograr su entrada a la célula hospedadora (42). La GRP78 es una proteína de choque térmico codificada por el gen HSPA5 que juega un papel importante en el plegamiento de proteínas (46).

\section{Diagnóstico de COVID-19}

Las infecciones emergentes por $\mathrm{CoV}$ humanos $(\mathrm{CoVH})$ han propiciado el desarrollo de métodos de diagnóstico rápidos, sensibles y específicos. Desde pruebas moleculares tipo reacción en cadena de la polimerasa con transcriptasa inversa (RT-PCR) hasta dispositivos moleculares integrados, de acceso aleatorio y en el punto de atención (POCT, por sus siglas en inglés de Point-of-care testing), altamente seguros para el personal de salud y accesibles en hospitales y clínicas a nivel mundial.

Debe tenerse en cuenta que, a pesar de la precisión y rapidez de los métodos utilizados en el laboratorio, el diagnóstico oportuno de neumonías virales como la causada por el SARS-CoV-2 implica recolectar una óptima muestra del paciente: del lugar indicado, con los cepillos recolectores recomen- 
dados, en la cantidad necesaria y el momento adecuado.

\section{Pruebas de laboratorio para SARS-CoV-2}

\section{RT-PCR}

Tan pronto como se conoció la secuencia viral de SARS-CoV-2, la PCR acoplada a transcripción reversa, fue el primer método empleado para diagnosticar COVID-19, debido a que las sondas de hidrólisis y cebadores necesarios para la detección de genes diana específicos se pueden producir rápidamente (Figura 4E).

En enero, la OMS se encargó del diseño y distribución de las primeras RT-PCR para detectar SARS-CoV-2. Este protocolo es complejo y costoso, tarda entre 4 a 6 horas y requiere el envío de las muestras clínicas a laboratorios de diagnóstico grandes y centralizados, por lo que requiere de personal profesional y el tiempo de respuesta es de máximo 24 horas (47).

\section{Pruebas rápidas de antígeno}

Ofrecen economía y obtención de resultados en un tiempo corto, aunque en ocasiones a expensas de la sensibilidad de detección, como se ha visto en otros casos, por ejemplo, con los virus de influenza $(48,49)$. No obstante, el ensayo inmunocromatográfico de fluorescencia para el diagnóstico de COVID-19 propuesto por Diao et al, podría ser un método preciso para detectar en 10 minutos la proteína de la nucleocápside del nuevo coronavirus a partir de una muestra tomada con un hisopo nasofaríngeo. Esta proteína también se pudo detectar en la orina del $73 \%$ de los pacientes diagnosticados evaluados en este estudio (Figura 4B) (50).

Aparte de recolectar la muestra cuando los títulos virales son más altos, otra de las medidas que se pueden implementar en la práctica clínica ambulatoria para aumentar la sensibilidad diagnóstica de las pruebas rápidas de antígeno, y que ya ha funcionado antes en la detección de los virus de la influenza $\mathrm{A}$ y $\mathrm{B}$, es la conjugación de anticuerpos monoclonales al oro coloidal como reactivo de detección rápida de virus respiratorios (51).

\section{Ensayos serológicos}

No se usan rutinariamente para diagnosticar infecciones por $\mathrm{CoV}$, su importancia radica en la comprensión de la epidemiología de los CoVH emergentes y en el papel de las infecciones asintomáticas, que al parecer son más frecuentes de lo que se creía (52). Para el 12 de marzo, en China, seis ensayos serológicos ya tenían la aprobación urgente de la Administración Nacional de Productos Médicos (tabla 1, figura 5A).

Recientemente, se demostró la detección de anticuerpos IgM e IgG, 5 días después del inicio de los síntomas en 39 pacientes infectados con SARS-CoV-2 (53). La serología se podría indicar para diagnóstico 
complementario cuando las pruebas rápidas de antígeno no estén disponibles, cuando la muestra recolectada no tenga la calidad ne- cesaria para realizar ensayos moleculares o cuando estos ensayos no pasen los controles requeridos.

Tabla 1. Ensayos serológicos autorizados en China para el diagnóstico de laboratorio de infecciones por SARS-CoV-2.

\begin{tabular}{|c|c|c|c|c|}
\hline Método & Fabricante & Características & Objetivos & Ref \\
\hline $\begin{array}{l}\text { Técnica inmunológica de } \\
\text { oro coloidal }\end{array}$ & Wondfo Biotech & $\begin{array}{c}\text { Inmunoensayo de flujo lateral de } 15 \\
\text { minutos }\end{array}$ & $\begin{array}{c}\text { Anticuerpos IgM/IgG contra } \\
\text { SARS-CoV-2 }\end{array}$ & $(54,55)$ \\
\hline $\begin{array}{l}\text { Técnica inmunológica de } \\
\text { oro coloidal }\end{array}$ & $\begin{array}{l}\text { Innovita Biological } \\
\text { Technology }\end{array}$ & $\begin{array}{c}\text { Inmunoensayo de flujo lateral de } 15 \\
\text { minutos }\end{array}$ & $\begin{array}{c}\text { Anticuerpos IgM/IgG contra } \\
\text { SARS-CoV-2 }\end{array}$ & (56) \\
\hline $\begin{array}{l}\text { Quimioluminiscencia de } \\
\text { partículas magnéticas. }\end{array}$ & Bioscience (Chongqing) & $\begin{array}{l}\text { Utilizando el analizador magnético } \\
\text { automatizado: Axceed } 260\end{array}$ & $\begin{array}{l}\text { Anticuerpos IgM contra SARS- } \\
\text { CoV-2 }\end{array}$ & (57) \\
\hline $\begin{array}{l}\text { Quimioluminiscencia de } \\
\text { partículas magnéticas. }\end{array}$ & Bioscience (Chongqing) & $\begin{array}{l}\text { Utilizando el analizador magnético } \\
\text { automatizado: Axceed } 260\end{array}$ & $\begin{array}{l}\text { Anticuerpos IgG contra SARS- } \\
\text { CoV-2 }\end{array}$ & (57) \\
\hline $\begin{array}{l}\text { Inmunoensayo de } \\
\text { micropartículas } \\
\text { quimioluminiscente }\end{array}$ & $\begin{array}{l}\text { Xiamen Wantai Kairui } \\
\text { Biotechnology }\end{array}$ & $\begin{array}{c}\text { Tiempo de respuesta, } 29 \text { min; } \\
\text { Rendimiento, } 400 \text { pruebas / hora; } \\
\text { Sensibilidad, 94,8\%; Especificidad, 99,7\% } \\
\text { Usando el analizador automático de } \\
\text { quimioluminiscencia Caris } 200\end{array}$ & $\begin{array}{l}\text { Anticuerpos totales (IgM, IgG e } \\
\text { IgA) contra SARS-CoV-2 }\end{array}$ & (57) \\
\hline $\begin{array}{l}\text { Técnica inmunológica de } \\
\text { oro coloidal }\end{array}$ & $\begin{array}{l}\text { Guangdong Hexin Health } \\
\text { Technology Co }\end{array}$ & Detección rápida y cualitativa & $\begin{array}{l}\text { Anticuerpos IgM contra SARS- } \\
\text { CoV-2 }\end{array}$ & (57) \\
\hline
\end{tabular}

Fuente: Autores.

\section{Secuenciación}

La secuenciación genética es la forma más precisa y confiable de identificar el SARS$\mathrm{CoV}-2$, además, proporciona una base efectiva para el posterior desarrollo de kits de RT-PCR sensibles y específicos, es la única forma de rastrear las mutaciones del virus, puede brindar información valiosa para el desarrollo de vacunas, para realizar estu- dios sobre el mecanismo de patogenicidad, propagación y epidemiología genética de SARS-CoV-2 con el fin orientar de mejor manera las medidas de prevención.

Inicialmente, se utilizó el sistema de secuenciación DNBSEQ-T7 de ultra alto rendimiento de MGI Tech, cuya tasa de precisión puede alcanzar el $100 \%$ y puede completar todo el proceso de detección des- 
de la extracción de ácidos nucleicos hasta el informe de resultados en 20 - 22 horas (58). Sin embargo, el costo es alto, la operación es complicada y no es adecuada para la detección de rutina en una clínica (Figura 4F).

\section{Amplificación isotérmica en chip de sistema de microfluídica}

La amplificación y las reacciones son isotérmicas en función del efecto sinérgico de la transcripción inversa y la transcriptasa, utilizando sondas fluorescentes específicas para la detección de fluorescencia en tiempo real.

Es un ensayo de alta precisión que emplea chips microfluídicos, controles de calidad, tecnología anticontaminación y tiene una alta sensibilidad en la detección simultánea de múltiples genes objetivo, incluyendo SARS-CoV-2, virus de la gripe A, virus de la gripe $\mathrm{H} 1 \mathrm{~N} 1$, virus de la gripe A H3N2, virus de la gripe $\mathrm{B}$, virus sincitial respiratorio y otros patógenos, con el fin de descartar diferentes etiologías, optimizar los recursos del sistema de salud y conocer el porcentaje de coinfecciones.

Las muestras positivas crearán una curva de amplificación de aspecto sigmoideo similar a la PCR de fluorescencia en tiempo real, los resultados se interpretan con ayuda de un software y generalmente toma 1,5 horas. Sin embargo, algunos patógenos pueden pasarse por alto (Figura 4H) (59).

\section{Inmunoensayo magnético quimiolu- miniscente}

Este ensayo emplea péptidos sintéticos de SARS-CoV-2, sintetizados a partir de la secuencia genómica, para detectar anticuerpos contra este CoV. Para garantizar una alta especificidad, la región escogida debe tener una homología baja en relación con otros CoV. Los péptidos biotinilados y purificados están unidos a perlas magnéticas recubiertas con estreptavidina. Las perlas se hacen reaccionar con los anticuerpos conjugados y con el sustrato (Figura 5B) (60). Este método es altamente sensible, específico, reproducible y completamente automatizado, los resultados generalmente se producen en 30 minutos. Sin embargo, se requiere un equipo especial de detección de quimioluminiscencia.

\section{Amplificación isotérmica de ácidos nucleicos}

Ensayo automatizado que detecta ácidos nucleicos virales específicos de SARSCoV-2 utilizando tecnología de amplificación a la misma temperatura. Las plantillas (similares a los cebadores) se dirigen al ARN de SARS-CoV-2 y amplifican una región única. Se utilizan balizas moleculares marcadas con fluorescencia para identificar específicamente cada una de las dianas de ARN amplificadas. En comparación con el método de PCR fluorescente, los requisitos del equipo son menores, proporciona calentamiento, mezcla y detección, y general- 
mente se obtienen resultados en 15 minutos (Figura 4G) (61).

\section{Método de inmunofluorescencia de captura híbrida}

Sistema de detección rápida in situ de los ácidos nucleicos de SARS-CoV-2 en un solo paso. No requiere extracción, purificación de ácidos nucleicos, ni amplificación por PCR. El ARN y la sonda específica forman híbridos (ARN/ADN) que son identificados por anticuerpos específicos y una solución quimioluminiscente. La fluorescencia emitida se mide en un luminómetro, obteniendo resultados cualitativos de la presencia del virus. Estos kits de prueba se pueden almacenar y transportar a temperatura ambiente, lo cual minimiza la logística necesaria de la cadena de frío, el tamaño del equipo de detección es pequeño, portátil y el tiempo de detección de una sola muestra es más corto, generalmente de 45 minutos a 1 hora (Figura 4A) (62).

\section{Hibridación competitiva de ADN y detección electroquímica}

Este método es altamente específico, no se basa en la detección fluorescente u óptica. Está diseñado para ser llevado a cabo por personal de laboratorio calificado y capacitado y requiere un equipo especial de detección.

La muestra y los reactivos se introducen en un cartucho y por medio de campos eléc- tricos se programa su desplazamiento para completar todas las partes del procesamiento de la muestra: extracción y purificación de ácidos nucleicos mediante extracción magnética en fase sólida; transcripción inversa seguida de PCR; y digestión con exonucleasa, obteniendo finalmente ADN monocatenario.

El ADN objetivo se hibrida con su sonda de señal complementaria marcada con ferroceno y con las sondas de captura, que están unidas a electrodos chapados en oro. El análisis electroquímico determina la presencia o ausencia de objetivos mediante voltamperometría, generando señales eléctricas específicas de la sonda de señal marcada con ferroceno (Figura 4D) (63).

\section{Pruebas rápidas basadas en CRISPR para SARS-CoV-2}

Método de detección de SARS-CoV-2 ultrasensible, rápido y portátil utilizando las enzimas Cas12 o Cas13 para la detección de huellas genéticas únicas. Una vez obtenido y amplificado el cDNA, se agregan los complejos de detección CRISPR, los cuales constan de una endonucleasa y un ARN guía dirigido a diferentes blancos de SARSCoV-2, por ejemplo, a los genes RdRp, ORF1b y ORF1ab.

La detección se logra con reporteros de ADN monocatenario (ADNss) ya sea etiquetado con FAM en un lector de placas, o etiquetado con biotina para la detección 
portátil con tiras de papel. Después del reconocimiento del objetivo, la endonucleasa induce la degradación colateral indiscriminada de los reporteros de ADNss, que emiten una señal de fluorescencia o pueden detectarse por flujo lateral en menos de 60 minutos (Figura 4C) (64).

Figura 4. Esquema ilustrativo resumido de los métodos diagnósticos para la detección de SARS-CoV-2.
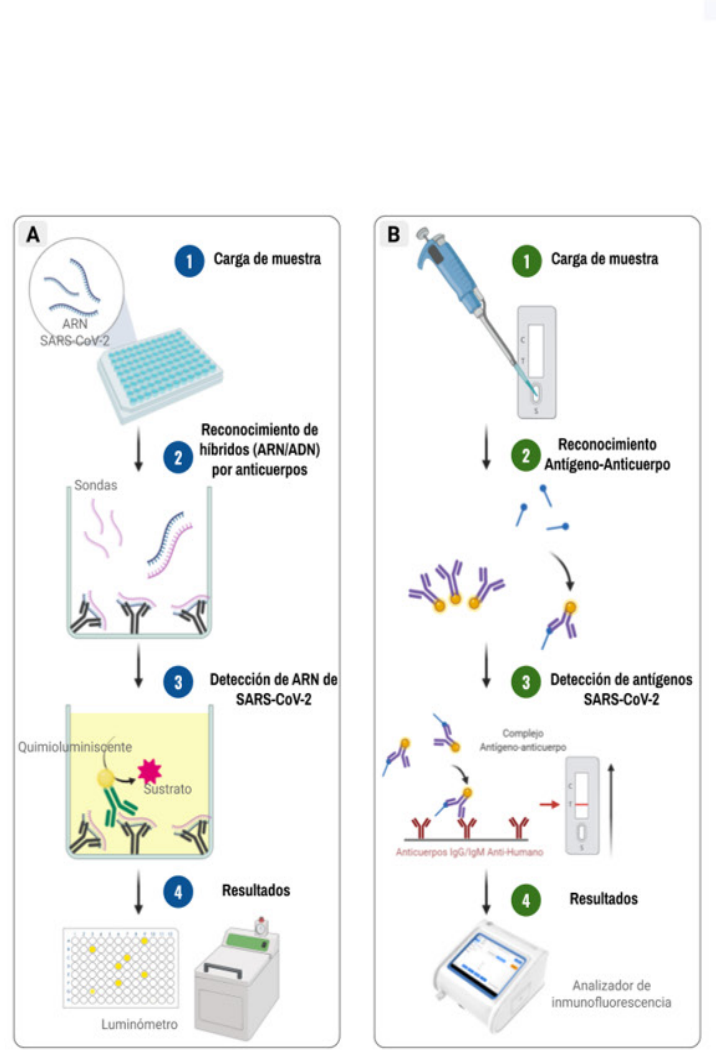

\section{Detección de SARS-CoV-2}
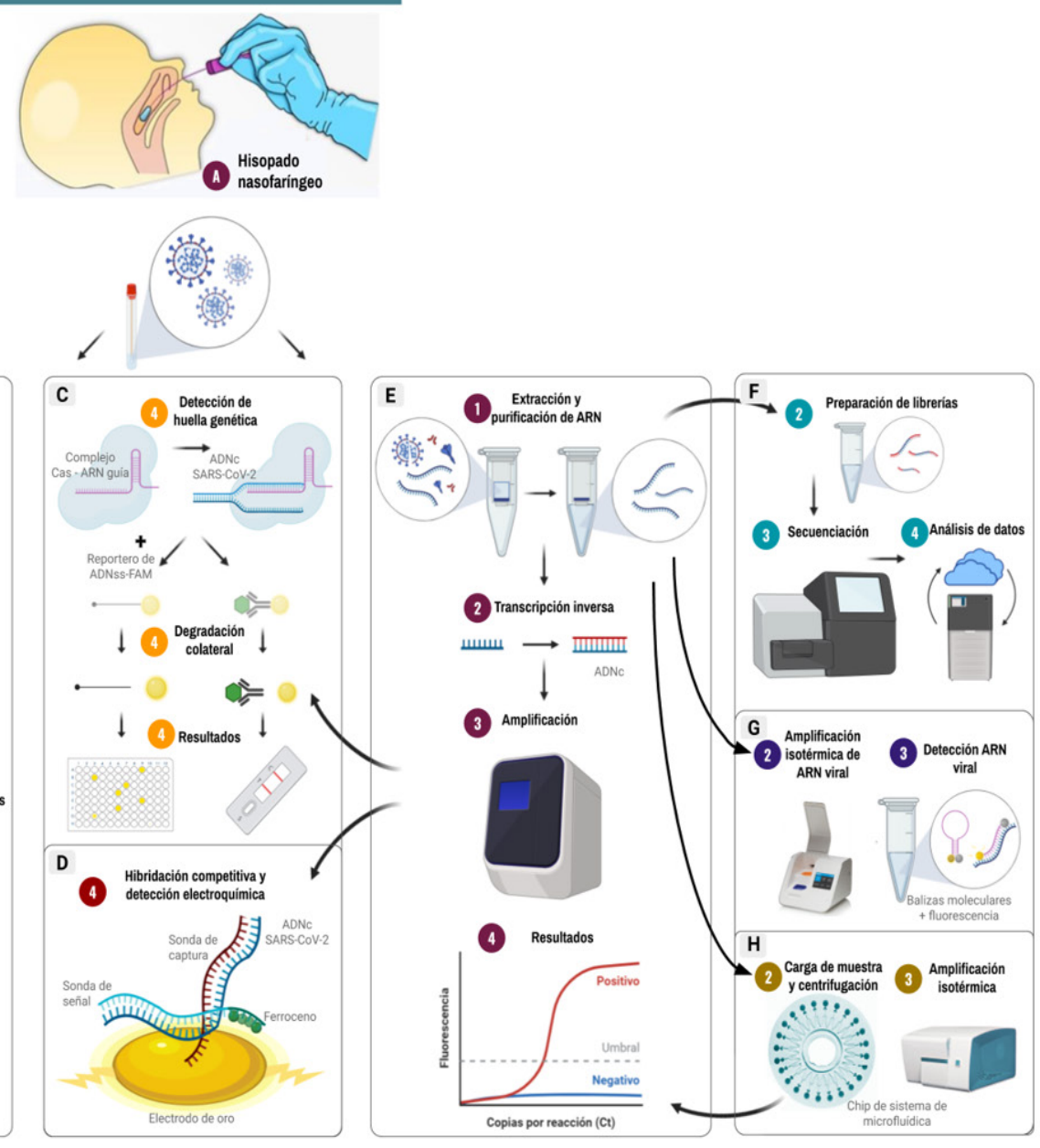

Fuente: Autores. 
Figura 5. Esquema ilustrativo resumido de los métodos diagnósticos para la detección de los anticuerpos contra SARSCoV-2.

\section{Deteceión de anticuerpos contra SARS-CoV-2}

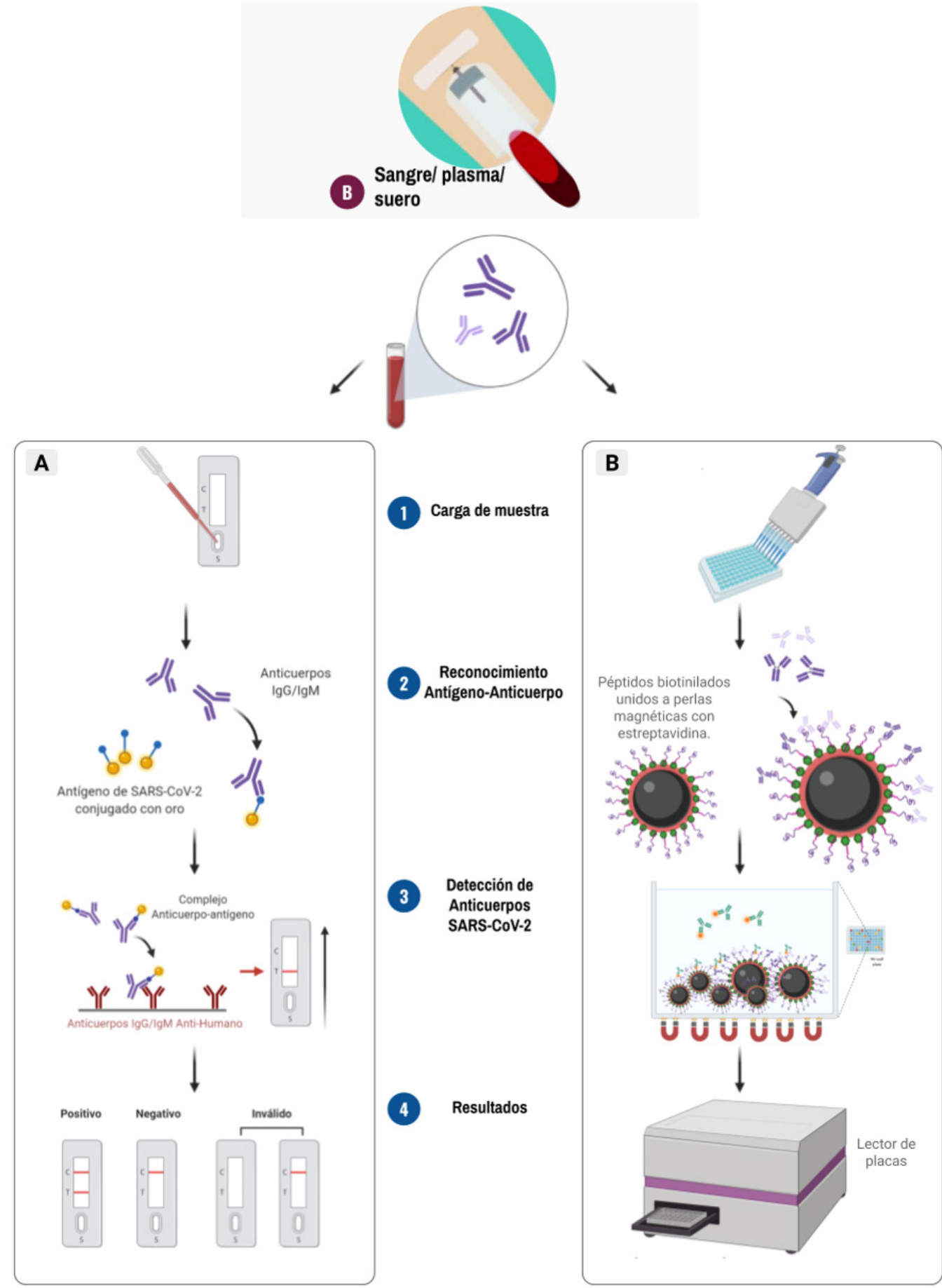

Fuente: Autores. 


\section{Teniendo en cuenta las tasas de mortali- de emergencia a las siguientes pruebas (ta- dad e infecciosidad asociadas a este nuevo bla 2).}

CoV, la FDA emitió autorizaciones de uso

Tabla 2. Pruebas diagnósticas con autorización de uso de emergencia para dispositivos médicos por parte de la FDA.

\begin{tabular}{|c|c|c|c|c|}
\hline Método & Nombre y Fabricante & Características & Solicitud & Ref \\
\hline $\begin{array}{l}\text { RT-PCR multiplexen } \\
\text { tiempo real }\end{array}$ & $\begin{array}{l}\text { ARIES SARS-CoV-2 } \\
\text { Assay (Luminex } \\
\text { Corporation) }\end{array}$ & $\begin{array}{l}\text { Se ejecuta en el sistema ARIES } \\
\text { automatizado y ofrece un resultado en dos } \\
\text { horas; el sistema puede ejecutar hasta } 144 \\
\text { pruebas por día }\end{array}$ & $\begin{array}{l}\text { Detección de los genes: ORF1ab } \\
\text { y N }\end{array}$ & (65) \\
\hline $\begin{array}{l}\text { Inmunoensayo } \\
\text { cromatográfico de flujo } \\
\text { lateral }\end{array}$ & $\begin{array}{l}\text { qSARS-CoV-2 IgG/IgM } \\
\text { Rapid Test } \\
\text { (Cellex Inc) }\end{array}$ & $\begin{array}{l}\text { Detecta anticuerpos antivirales en } 15 \text { a } 20 \\
\text { minutos, con un } 93,75 \% \text { de porcentaje de } \\
\text { acuerdo positivo y } 96,40 \% \text { de porcentaje } \\
\text { de acuerdo negativo. }\end{array}$ & $\begin{array}{c}\text { Anticuerpos IgM/IgG contra } \\
\text { SARS-CoV-2 }\end{array}$ & $(66)$ \\
\hline $\begin{array}{l}\text { PCR tiempo real } \\
\text { multiplex }\end{array}$ & $\begin{array}{l}\text { QIAstat-Dx Respiratory } \\
\text { SARS-CoV-2 Panel } \\
\text { (QIAGEN GmbH) }\end{array}$ & $\begin{array}{c}\text { Panel diseñado para la detección y } \\
\text { diferenciación de ácidos nucleicos de } \\
\text { SARS-CoV-2 y de otros } 20 \text { virus y } \\
\text { bacterias. }\end{array}$ & $\begin{array}{c}\text { Detección de los genes Rdrp y E } \\
\text { detectados con el mismo canal de } \\
\text { fluorescencia. }\end{array}$ & (67) \\
\hline RT-PCR tiempo real & $\begin{array}{c}\text { NeuMoDx SARS-CoV-2 } \\
\text { Assay (NeuMoDx } \\
\text { Molecular, Inc) }\end{array}$ & $\begin{array}{l}\text { Automatiza extracción de ARN por } \\
\text { microesferas magnéticas; amplificación } \\
\text { con el sistema NeuMoDx cuantitativo; } \\
\text { e identificación con cebadores y sondas } \\
\text { Taqman (fluoróforos FAM, HEX y Far- } \\
\text { Red) }\end{array}$ & Detección de los genes Nsp2 y N & $(68)$ \\
\hline RT-PCR e hibridación & $\begin{array}{l}\text { NxTAG CoV Extended } \\
\text { Panel Assay (Luminex } \\
\text { Molecular Diagnostics) }\end{array}$ & $\begin{array}{l}\text { Extracción de ácido nucleico con perlas } \\
\text { liofilizadas. Amplificación. Hibridación en } \\
\text { perlas etiquetadas. Clasificación y lectura } \\
\text { en el instrumento MAGPIX }\end{array}$ & $\begin{array}{l}\text { Detección de los genes: ORF1ab, } \\
\text { Gen N y Gen E. }\end{array}$ & (69) \\
\hline $\begin{array}{l}\text { Amplificación isotérmica } \\
\text { de ácidos nucleicos }\end{array}$ & $\begin{array}{l}\text { ID NOW COVID-19 } \\
\text { (Abbott Diagnostics } \\
\text { Scarborough) }\end{array}$ & $\begin{array}{l}\text { Utilización de balizas moleculares marcadas } \\
\text { con fluorescencia para identificar ARN } \\
\text { amplificado en el instrumento ID NOW. } \\
\text { Resultados en } 13 \text { minutos. }\end{array}$ & $\begin{array}{l}\text { Detección cualitativa de una } \\
\text { región única del segmento RdRp }\end{array}$ & (61) \\
\hline RT-PCR tiempo real & $\begin{array}{l}\text { Real-Time Fluorescent } \\
\text { RT-PCR Kit for Detecting } \\
\text { SARS-2019-nCoV } \\
\text { (BGI Genomics) }\end{array}$ & $\begin{array}{l}\text { Identificación con cebadores y sondas } \\
\text { Taqman con los fluoróforos FAM y VIC/ } \\
\text { HEX utilizando el termociclador ABI } 7500\end{array}$ & $\begin{array}{c}\text { Detección de una región específica } \\
\text { del gen ORF1ab }\end{array}$ & (70) \\
\hline RT-PCR tiempo real & $\begin{array}{l}\text { AvellinoCoV2 test } \\
\text { (Avellino Lab USA) }\end{array}$ & $\begin{array}{l}\text { Identificación con cebadores y sondas } \\
\text { Taqman con el fluoróforo FAM y el } \\
\text { extintor MGBNFQ, utilizando el } \\
\text { termociclador ABI } 7500\end{array}$ & $\begin{array}{l}\text { Detección de dos regiones en el } \\
\text { gen N de SARS-CoV-2 }\end{array}$ & (71) \\
\hline RT-PCR tiempo real & $\begin{array}{l}\text { New Coronavirus Nucleic } \\
\text { Acid Detection Kit } \\
\text { (PerkinElmer) }\end{array}$ & $\begin{array}{l}\text { Identificación con cebadores y sondas } \\
\text { Taqman con fluoróforos FAM, ROX } \\
\text { y VIC. Sistema de prevención de } \\
\text { transferencia UNG/dUTP para evitar la } \\
\text { contaminación. }\end{array}$ & Detección del gen N y ORF1ab. & $(72)$ \\
\hline
\end{tabular}




\begin{tabular}{|c|c|c|c|c|}
\hline $\begin{array}{l}\text { Prueba de amplificación } \\
\text { de ácido nucleico }\end{array}$ & $\begin{array}{l}\text { Accula SARS-CoV-2 Test } \\
\text { (Mesa Biotech) }\end{array}$ & $\begin{array}{l}\text { Lisis del virus, transcripción inversa, } \\
\text { amplificación de ácido nucleico y } \\
\text { detección en } 30 \text { minutos. Los resultados se } \\
\text { interpretan visualizando líneas azules en la } \\
\text { tira de detección en el casete de prueba. }\end{array}$ & $\begin{array}{l}\text { Detección cualitativa de ARN } \\
\text { viral de SARS-CoV- } 2 \text {. }\end{array}$ & (73) \\
\hline PCR multiplex anidada & $\begin{array}{l}\text { BioFire COVID-19 Test } \\
\text { (BioFire Defense, LLC) }\end{array}$ & $\begin{array}{l}\text { Sistema cerrado desechable para extraer } \\
\text { con perlas magnéticas, amplificar y detectar } \\
\text { ácidos nucleicos en } 50 \text { minutos en el } \\
\text { instrumento FilmArray. Interpretación de } \\
\text { resultados por análisis de curvas de fusión }\end{array}$ & $\begin{array}{l}\text { Detección del ORF8 y de dos } \\
\text { regiones en el ORF1ab }\end{array}$ & $(74)$ \\
\hline RT-PCR tiempo real & $\begin{array}{l}\text { Xpert Xpress SARS- } \\
\text { CoV-2 (Cepheid) }\end{array}$ & $\begin{array}{l}\text { Prueba en el punto de atención. } \\
\text { Extracción, amplificación y detección en } \\
\text { un cartucho integrado en } 45 \text { minutos para } \\
\text { los sistemas GeneXpert Dx y GeneXpert } \\
\text { Infinity. }\end{array}$ & Detección del gen N2 y E & $(75)$ \\
\hline PCR tiempo real & $\begin{array}{l}\text { Primerdesign Ltd } \\
\text { COVID-19 genesig Real- } \\
\text { Time PCR assay } \\
\text { (Primerdesign Ltd) }\end{array}$ & $\begin{array}{l}\text { Identificación con cebadores y sondas } \\
\text { Taqman marcadas con los fluoróforos FAM } \\
\text { y HEX. Utilizando los termocicladores: } \\
\text { ABI 7500, Roche LightCycler } 480 \text { II o } \\
\text { Bio-Rad CFX }\end{array}$ & Detección del ORF1ab & (76) \\
\hline $\begin{array}{l}\text { RT-PCR, hibridización } \\
\text { competitiva de ADN y } \\
\text { detección electroquímica. }\end{array}$ & $\begin{array}{l}\text { ePlex SARS-CoV-2 } \\
\text { (GenMark Diagnostics) }\end{array}$ & $\begin{array}{c}\text { Extracción magnética en fase sólida, } \\
\text { amplificación y detección. El ADN } \\
\text { objetivo se hibrida con la sonda de } \\
\text { captura (unida a un electrodo de oro) y } \\
\text { con una sonda de seńal complementaria } \\
\text { marcada con ferroceno. Se determina la } \\
\text { presencia o ausencia de objetivos mediante } \\
\text { voltamperometría }\end{array}$ & $\begin{array}{c}\text { Detección cualitativa de ácidos } \\
\text { nucleicos }\end{array}$ & $(63)$ \\
\hline RT-PCR tiempo real & $\begin{array}{l}\text { Simplexa COVID-19 } \\
\text { Direct assay (DiaSorin } \\
\text { Molecular LLC) }\end{array}$ & $\begin{array}{l}\text { Amplificación directa del ARN del SARS- } \\
\text { CoV-2 y del ARN control. Los cebadores } \\
\text { se usan junto con las sondas fluorescentes } \\
\text { marcadas con FAM, JOE y Q670. }\end{array}$ & $\begin{array}{c}\text { Detección cualitativa de los genes } \\
\text { ORF1ab y } S .\end{array}$ & (77) \\
\hline RT-PCR tiempo real & $\begin{array}{c}\text { Abbott RealTime SARS- } \\
\text { CoV-2 assay } \\
\text { (Abbott Molecular) }\end{array}$ & $\begin{array}{l}\text { Identificación con cebadores y sondas } \\
\text { marcadas con fluorescencia. Las sondas } \\
\text { específicas de SARS-CoV-2 están marcadas } \\
\text { con el mismo fluoróforo y la sonda del } \\
\text { control con un fluoróforo diferente. El } \\
\text { ensayo se realiza con los instrumentos } \\
\text { Abbott m2000, m2000sp y m2000rt. }\end{array}$ & $\begin{array}{c}\text { Detección cualitativa de los genes } \\
\text { RdRp y N. }\end{array}$ & (78) \\
\hline RT-PCR tiempo real & $\begin{array}{l}\text { Quest SARS-CoV-2 rRT- } \\
\text { PCR (Quest Diagnostics } \\
\text { Infectious Disease) }\end{array}$ & $\begin{array}{l}\text { Amplificación utilizando el termociclador } \\
\text { ABI } 7500 \text { y detección utilizando la química } \\
\text { TaqMan (sondas marcadas con FAM, } \\
\text { TAMRA y Q670). }\end{array}$ & $\begin{array}{l}\text { Detección cualitativa de dos } \\
\text { regiones del gen N (N1 y N3) }\end{array}$ & (79) \\
\hline $\begin{array}{l}\text { RT-PCR tiempo real } \\
\text { multiplex }\end{array}$ & $\begin{array}{l}\text { Lyra SARS-CoV-2 Assay } \\
\text { (Quidel Corporation) }\end{array}$ & $\begin{array}{l}\text { Extracción del ARN viral utilizando el } \\
\text { sistema easyMAG o EMAG. Identificación } \\
\text { con cebadores y sondas marcadas con } \\
\text { los fluoróforos FAM y Q670, con los } \\
\text { termocicladores: ABI 7500, Roche } \\
\text { LightCycler } 480 \text { o Qiagen Rotor-Gene }\end{array}$ & $\begin{array}{l}\text { Detección de una región } \\
\text { conservada del gen de la } \\
\text { poliproteína no estructural } \\
\text { (pplab) }\end{array}$ & $(80)$ \\
\hline RT-PCR tiempo real & $\begin{array}{l}\text { COVID-19 RT-PCR Test } \\
\text { (Laboratory Corporation } \\
\text { of America) }\end{array}$ & $\begin{array}{l}\text { Amplificación utilizando el termociclador } \\
\text { ABI QuantStudio } 7 \text { Flex. y detección con } \\
\text { sondas marcadas con FAM. }\end{array}$ & $\begin{array}{c}\text { Detección de tres regiones del gen } \\
\mathrm{N} \text { de SARS-CoV-2 }\end{array}$ & $(81)$ \\
\hline
\end{tabular}




\begin{tabular}{|c|c|c|c|c|}
\hline $\begin{array}{l}\text { RT-PCR tiempo real } \\
\text { multiplex }\end{array}$ & $\begin{array}{l}\text { Panther Fusion SARS- } \\
\text { CoV-2 (Hologic, Inc.) }\end{array}$ & $\begin{array}{l}\text { Hibridación del ácido nucleico presente } \\
\text { en la muestra con oligonucleótidos de } \\
\text { captura y posterior separación en un } \\
\text { campo magnético. Amplificación de dos } \\
\text { regiones del virus y detección con el mismo } \\
\text { fluoróforo (ROX). Fluorescencia analizada } \\
\text { en el sistema Panther Fusion. }\end{array}$ & $\begin{array}{l}\text { Detección cualitativa de dos } \\
\text { regiones conservadas del gen } \\
\text { ORF1ab en el mismo canal de } \\
\text { fluorescencia. }\end{array}$ & $(82)$ \\
\hline $\begin{array}{l}\text { RT-PCR tiempo real } \\
\text { multiplex }\end{array}$ & $\begin{array}{l}\text { TaqPath COVID-19 } \\
\text { Combo Kit (Thermo } \\
\text { Fisher Scientific, Inc.) }\end{array}$ & $\begin{array}{l}\text { Identificación con cuatro conjuntos de } \\
\text { cebadores y sondas marcadas con diferentes } \\
\text { fluoróforos: tres para diferentes regiones } \\
\text { genómicas de SARS-CoV-2 (FAM, VIC y } \\
\text { ABY) y uno para el control (JUN) }\end{array}$ & $\begin{array}{c}\text { Detección cualitativa de los genes } \\
\text { ORF1ab, N y S }\end{array}$ & (83) \\
\hline RT-PCR tiempo real & $\begin{array}{l}\text { cobas SARS-CoV-2 } \\
\text { (Roche Molecular } \\
\text { Systems, Inc.) }\end{array}$ & $\begin{array}{l}\text { Preparación de muestras automatizadas, } \\
\text { de amplificación y detección en el } \\
\text { sistema cobas } 6800 \text { y } 8800 \text { con sondas de } \\
\text { detección de coronavirus y de un control } \\
\text { interno de ARN marcadas con colorantes } \\
\text { fluorescentes únicos. La mezcla maestra } \\
\text { incluye dUTP, en lugar de dTTP, que se } \\
\text { incorpora al amplicón. La enzima uracil- } \\
\text { N-glucosilasa destruye los amplicones } \\
\text { contaminantes. }\end{array}$ & $\begin{array}{l}\text { Detección cualitativa del gen } \\
\text { ORF1ab y de una región } \\
\text { conservada en el gen E de la } \\
\text { envoltura del pan-Sarbecovirus, } \\
\text { la cual también detecta el virus } \\
\text { SARS-CoV-2. }\end{array}$ & (84) \\
\hline RT-PCR tiempo real & $\begin{array}{l}\text { New York SARS-CoV-2 } \\
\text { Real-time Reverse } \\
\text { Transcriptase (RT)- } \\
\text { PCR Diagnostic Panel } \\
\text { (Wadsworth Center) }\end{array}$ & $\begin{array}{l}\text { Identificación con dos juegos de cebadores } \\
\text { y sondas Taqman y uno adicional para el } \\
\text { gen RP humano en el instrumento ABI } \\
7500 \text { Fast Dx }\end{array}$ & $\begin{array}{c}\text { Detección de dos regiones del } \\
\text { gen } \mathrm{N}\end{array}$ & $(85)$ \\
\hline RT-PCR tiempo real & $\begin{array}{l}\text { CDC 2019-nCoV Real- } \\
\text { Time RT-PCR Diagnostic } \\
\text { Panel (CDC) }\end{array}$ & $\begin{array}{c}\text { Identificación con dos juegos de cebadores } \\
\text { y sondas Taqman y uno adicional para el } \\
\text { gen RP humano en el instrumento ABI } \\
7500 \text { Fast Dx }\end{array}$ & $\begin{array}{c}\text { Detección de dos regiones del } \\
\text { gen } \mathrm{N}\end{array}$ & (86) \\
\hline
\end{tabular}

Fuente: Autores.

\section{Conclusiones}

Teniendo en cuenta que la OMS y el CDC han determinado que la RT-PCR es el estándar de oro actual para el diagnóstico de la infección por SARS-CoV-2, y que esta ha demostrado una baja positividad en muestras de hisopados de garganta de pacientes sintomáticos, una posible forma de aumentar la sensibilidad en la detección de SARSCoV-2 es implementando la PCR digital (87).
La tecnología de PCR digital podría aumentar la sensibilidad diagnóstica de individuos con bajos títulos virales de SARS$\mathrm{CoV}-2$ que se encuentran bajo aislamiento y aquellos bajo observación que pueden no presentar síntomas clínicos, como se ha evidenciado en los infectados presintomáticos, asintomáticos y las personas adultas mayores que están en proceso de recuperación en quienes las pruebas moleculares actuales los detectan como recuperados pero todavía no han eliminado del todo al SARS-CoV-2 de 
su sistema. Recientemente, se ha evidenciado que la PCR digital podría disminuir el límite de detección inferior en al menos 500 veces en comparación con el de la RTPCR, así como el porcentaje de falsos negativos de la RT-PCR estándar actual (88).

Adicionalmente, en vista de que la RT-PCR requiere de la extracción de $A R N$ por medio de kits que actualmente escasean a nivel mundial y han causado un grave cuello de botella en las pruebas para diagnosticar COVID-19, se ha propuesto un protocolo en el que se detecta directamente el ARN del SARS-CoV-2 a partir de muestras nasofaríngeas a través de un ensayo directo de PCR omitiendo el paso de extracción de ARN y reduciendo el tiempo de obtención de resultados (89).

Considerando que, la práctica clínica actual dicta que el convaleciente por COVID-19 debe continuar en cuarentena durante 2 semanas, la alta sensibilidad de la PCR digital, ayudaría a disminuir el tiempo de aislamiento de los pacientes recuperados otorgando un resultado negativo más confiable para agilizar la atención, optimizar los recursos y evitar colapsar los sistemas de salud.

\section{Referencias}

1. Comisión Municipal de Salud de Wuhan. Informe de la Comisión Municipal de Salud de Wuhan sobre la situación actual de epidemia de neumonía en nuestra ciudad. 2019 Dec 31 [cited 2020 Mar 15]; Available from: http://wjw.wuhan.gov.cn/front/ web/showDetail/2019123108989
2. Organización Mundial de la Salud. Novel Coronavirus - China. 2020 Jan 12 [cited 2020 Mar 15]; Available from: https://www.who.int/csr/ don/12-january-2020-novel-coronavirus-china/en/

3. Organización Mundial de la Salud. Naming the coronavirus disease (COVID-19) and the virus that causes it. 2020 [cited 2020 Mar 15]; Available from: https://www.who.int/emergencies/diseases/ novel-coronavirus-2019/technical-guidance/naming-the-coronavirus-disease-(covid-2019)-andthe-virus-that-causes-it

4. Organización Mundial de la Salud. Declaración sobre la segunda reunión del Comité de Emergencias del Reglamento Sanitario Internacional (2005) acerca del brote del nuevo coronavirus (2019-nCoV). 2020 Jan 30 [cited 2020 Apr 9]; Available from: https://www.who. int/es/news-room/detail/30-01-2020-statement-on-the-second-meeting-of-the-international-health-regulations-(2005)-emergency-committee-regarding-the-outbreak-of-novel-coronavirus-(2019-ncov)

5. Organización Mundial de la Salud. Alocución de apertura del Director General de la OMS en la rueda de prensa sobre la COVID-19 celebrada el 11 de marzo de 2020. 2020 Mar 11 [cited 2020 Apr 9]; Available from: https://www.who.int/es/dg/ speeches/detail/who-director-general-s-openingremarks-at-the-media-briefing-on-covid-19---11march-2020

6. Organización Mundial de la Salud. Summary of probable SARS cases with onset of illness from 1 November 2002 to 31 July 2003. 2003 Dec 31 [cited 2020 Mar 15]; Available from: https://www. who.int/csr/sars/country/table2004_04_21/en/

7. Organización Mundial de la Salud. Middle East respiratory syndrome coronavirus (MERS-CoV). 2020 [cited 2020 Mar 15]; Available from: https:// www.who.int/emergencies/mers-cov/en/

8. Organización Mundial de la Salud. 10 amenazas a la salud mundial en 2018. 2018 Feb [cited 2020 
Apr 9]; Available from: https://www.who.int/features/2018/10-threats-global-heath/es/

9. Menachery VD, Yount BL, Debbink K, Agnihothram S, Gralinski LE, Plante JA, et al. A SARS-like cluster of circulating bat coronaviruses shows potential for human emergence. Nat Med [Internet]. 2015;21:1508-1513. Available from: https:// www.nature.com/articles/nm.3985

10. Fehr AR, Perlman S. Coronaviruses: An overview of their replication and pathogenesis. In: Maier H, Bickerton E, Britton P (eds) Coronaviruses Methods in Molecular Biology, vol 1282. Humana Press, New York, NY; 2015. p. 1984-2020.

11. Song Z, Xu Y, Bao L, Zhang L, Yu P, Qu Y, et al. From SARS to MERS, thrusting coronaviruses into the spotlight. Viruses. 2019;11(1):59.

12. Reusken CEM, Haagmans BL, Koopmans MPG. Dromedary camels and Middle East respiratory syndrome: MERS coronavirus in the "ship of the desert.” Ned Tijdschr Geneeskd. 2014;158:A7806.

13. Wang LF, Eaton BT. Bats, civets and the emergence of SARS. In: Childs J.E., Mackenzie J.S. RJ., editor. Wildlife and Emerging Zoonotic Diseases: The Biology, Circumstances and Consequences of Cross-Species Transmission Current Topics in Microbiology and Immunology, vol 315. Springer, Berlin, Heidelberg; 2007.

14. Cui J, Li F, Shi ZL. Origin and evolution of pathogenic coronaviruses. Nat Rev Microbiol. 2019;17:181-192.

15. Organización Mundial de la Salud. Orientaciones técnicas sobre el nuevo coronavirus (2019-nCoV). [cited 2020 Apr 9]; Available from: https://www. who.int/es/emergencies/diseases/novel-coronavirus-2019/technical-guidance

16. Organización Mundial de la Salud. Brote de enfermedad por coronavirus (COVID-19): orientaciones para el público. [cited 2020 Apr 9]; Available from: https://www.who.int/es/emergencies/diseases/novel-coronavirus-2019/advice-for-public
17. Reuters. Wuhan lockdown "unprecedented", shows commitment to contain virus: WHO representative in China. 2020 Jan 23 [cited 2020 Mar 15]; Available from: https://www.reuters.com/article/ us-china-health-who/wuhan-lockdown-unprecedented-shows-commitment-to-contain-virus-who-representative-in-china-idUSKBN1ZM1G9

18. BBC News Mundo. Coronavirus: 5 estrategias que están funcionando en los países que han logrado contener los contagios de covid-19. 2020 Mar 17 [cited 2020 Mar 27]; Available from: https://www. bbc.com/mundo/noticias-internacional-51919935

19. Worldometer. Coronavirus Cases [Internet]. Worldometer. 2020 [cited 2020 Apr 27]. p. 1-22. Available from: https://www.worldometers.info/coronavirus/coronavirus-cases/\#daily-cases

20. Instituto Nacional de Salud. Coronavirus en Colombia. [cited 2020 Apr 27]; Available from: https://www.ins.gov.co/Noticias/Paginas/Coronavirus.aspx

21. Chan JFW, Yuan S, Kok KH, To KKW, Chu H, Yang J, et al. A familial cluster of pneumonia associated with the 2019 novel coronavirus indicating person-to-person transmission: a study of a family cluster. Lancet. 2020 Feb 15;395(10223):514-23.

22. Tong Z-D, Tang A, Li K-F, Li P, Wang H-L, Yi J-P, et al. Potential Presymptomatic Transmission of SARS-CoV-2, Zhejiang Province, China, 2020. Emerg Infect Dis. 2020 May;26(5):1052-4.

23. Bai Y, Yao L, Wei T, Tian F, Jin DY, Chen L, et al. Presumed Asymptomatic Carrier Transmission of COVID-19. JAMA - J Am Med Assoc. 2020;323(14):1406-1407.

24. Zheng J. SARS-CoV-2: an Emerging Coronavirus that Causes a Global Threat. Int J Biol Sci. 2020 Mar 21;16(10):1678-85.

25. Doremalen N van, Bushmaker T, Morris D, Holbrook M, Gamble A, Williamson B, et al. Aerosol and Surface Stability of SARS-CoV-2 as Compared 
with SARS-CoV-1. N Engl J Med. 2020;382:15647.

26. Yeo C, Kaushal S, Yeo D. Enteric involvement of coronaviruses: is faecal-oral transmission of SARSCoV-2 possible? Lancet Gastroenterol Hepatol. 2020 Apr 1;5(4):335-7.

27. Lu C wei, Liu X fen, Jia Z fang. 2019-nCoV transmission through the ocular surface must not be ignored. Lancet. 2020 Feb 22;395(10224):e39.

28. Worldometer. Coronavirus Incubation Period (COVID-19). 2020 Mar 12 [cited 2020 Mar 27]; Available from: https://www.worldometers.info/ coronavirus/coronavirus-incubation-period/

29. Wu JT, Leung K, Leung GM. Nowcasting and forecasting the potential domestic and international spread of the 2019-nCoV outbreak originating in Wuhan, China: a modelling study. Lancet [Internet]. 2020 Feb;395(10225):689-97. Available from: https://linkinghub.elsevier.com/retrieve/pii/ S0140673620302609

30. Organización Mundial de la Salud. Nuevo coronavirus - República de Corea (procedente de China). 2020 Jan 21 [cited 2020 Apr 9]; Available from: https://www.who.int/csr/don/21-january-2020-novel-coronavirus-republic-of-korea-ex-china/es/

31. Ministerio de Salud y Protección Social. Lineamientos para Prevención Control y Reporte de Accidente Laboral por Exposición Ocupacional al SARS CoV-2 (COVID-19) en Instituciones de Salud [Internet]. Bogotá, Colombia; 2020 [cited 2020 Apr 9]. Available from: https://www.minsalud.gov.co/Ministerio/Institucional/Procesos y procedimientos/GPSG04.pdf

32. Ministerio de Salud y Protección Social. Resolución número 385 del 12 de marzo de 2020 [Internet]. Bogotá, Colombia; [cited 2020 Apr 15]. Available from: https://www.minsalud.gov.co/sites/rid/Lists/BibliotecaDigital/RIDE/DE/DIJ/resolucion-385-de-2020.pdf

33. Lu R, Zhao X, Li J, Niu P, Yang B, Wu H, et al. Ge- nomic characterisation and epidemiology of 2019 novel coronavirus: implications for virus origins and receptor binding. Lancet. 2020;395(10224):56574.

34. Du L, He Y, Zhou Y, Liu S, Zheng BJ, Jiang S. The spike protein of SARS-CoV - A target for vaccine and therapeutic development. Nat Rev Microbiol. 2009;7(3):226-36.

35. Liu Z, Xiao X, Wei X, Li J, Yang J, Tan H, et al. Composition and divergence of coronavirus spike proteins and host ACE2 receptors predict potential intermediate hosts of SARS-CoV-2. J Med Virol. 2020;92:595-601.

36. Wan Y, Shang J, Graham R, Baric RS, Li F. Receptor Recognition by the Novel Coronavirus from Wuhan: an Analysis Based on Decade-Long Structural Studies of SARS Coronavirus. J Virol. 2020;94(7):e00127-20.

37. Ziebuhr J, Siddell SG. Processing of the Human Coronavirus 229E Replicase Polyproteins by the Virus-Encoded 3C-Like Proteinase: Identification of Proteolytic Products and Cleavage Sites Common to pp1a and pp1ab. J Virol. 1999;73(1):177185.

38. Zhang H, Penninger JM, Li Y, Zhong N, Slutsky AS. Angiotensin-converting enzyme 2 (ACE2) as a SARS-CoV-2 receptor: molecular mechanisms and potential therapeutic target. Intensive Care Med. 2020;46(4):586-90.

39. Deng X, StJohn SE, Osswald HL, O’Brien A, Banach BS, Sleeman K, et al. Coronaviruses Resistant to a 3C-Like Protease Inhibitor Are Attenuated for Replication and Pathogenesis, Revealing a Low Genetic Barrier but High Fitness Cost of Resistance. J Virol. 2014;88(20):11886-98.

40. Ibrahim IM, Abdelmalek DH, Elshahat ME, Elfiky AA. COVID-19 spike-host cell receptor GRP78 binding site prediction. J Infect. 2020;80(5):55462.

41. Wang Q, Qiu Y, Li JY, Zhou ZJ, Liao CH, Ge XY. 
A Unique Protease Cleavage Site Predicted in the Spike Protein of the Novel Pneumonia Coronavirus (2019-nCoV) Potentially Related to Viral Transmissibility. Virol Sin. 2020;20:1-3.

42. Robson B. Computers and viral diseases. Preliminary bioinformatics studies on the design of a synthetic vaccine and a preventative peptidomimetic antagonist against the SARS-CoV-2 (2019-nCoV, COVID-19) coronavirus. Comput Biol Med. 2020;119:103670.

43. Wrapp D, Wang N, Corbett KS, Goldsmith JA, Hsieh CL, Abiona O, et al. Cryo-EM structure of the 2019-nCoV spike in the prefusion conformation. Science (80- ). 2020;367(6483):1260-3.

44. Li W, Moore MJ, Vasllieva N, Sui J, Wong SK, Berne MA, et al. Angiotensin-converting enzyme 2 is a functional receptor for the SARS coronavirus. Nature. 2003;426(6965):450-4.

45. Hoffmann M, Kleine-Weber H, Krüger N, Müller M, Drosten C, Pöhlmann S. The novel coronavirus 2019 (2019-nCoV) uses the SARS-coronavirus receptor ACE2 and the cellular protease TMPRSS2 for entry into target cells. bioRxiv. 2020;

46. Ibrahim IM, Abdelmalek DH, Elfiky AA. GRP78: A cell's response to stress. Life Sci. 2019;226:15663.

47. Organización Mundial de la Salud. PCR protocol. [cited 2020 Apr 27]; Available from: https://www. who.int/docs/default-source/coronaviruse/whoinhouseassays.pdf?sfvrsn=de3a76aa_2

48. Chen Y, Chan KH, Hong C, Kang Y, Ge S, Chen $\mathrm{H}$, et al. A highly specific rapid antigen detection assay for on-site diagnosis of MERS. J Infect. 2016;73(1):82-4.

49. Lau SKP, Woo PCY, Wong BHL, Tsoi HW, Woo GKS, Poon RWS, et al. Detection of severe acute respiratory syndrome (SARS) coronavirus nucleocapsid protein in SARS patients by enzyme-linked immunosorbent assay. J Clin Microbiol. 2004;42(7):2884-9.
50. Diao B, Wen K, Chen J, Liu Y, Yuan Z, Han C, et al. Diagnosis of Acute Respiratory Syndrome Coronavirus 2 Infection by Detection of Nucleocapsid Protein. medRxiv. 2020;

51. Li W, Liu L, Chen L, Shang S. Evaluation of a Commercial Colloidal Gold Assay for Detection of Influenza A and B Virus in Children's Respiratory Specimens. Fetal Pediatr Pathol. 2019 Jul 15;39(2):93-8.

52. Chan CM, Tse H, Wong SSY, Woo PCY, Lau SKP, Chen L, et al. Examination of seroprevalence of coronavirus HKU1 infection with $S$ protein-based ELISA and neutralization assay against viral spike pseudotyped virus. J Clin Virol. 2009;45(1):5460.

53. Zhang W, Du RH, Li B, Zheng XS, Yang X Lou, $\mathrm{Hu} \mathrm{B}$, et al. Molecular and serological investigation of 2019-nCoV infected patients: implication of multiple shedding routes. Emerg Microbes Infect. 2020;9(1):386-9.

54. Wondfo. SARS-CoV-2 Antibody Test(Lateral Flow Method) [Internet]. [cited 2020 Apr 9]. Available from: https://en.wondfo.com.cn/product/wondfosars-cov-2-antibody-test-lateral-flow-method-2/

55. Wondfo. Chinese testing kit exports soar as COVID-19 spreads [Internet]. [cited 2020 Apr 8]. Available from: https://en.wondfo.com. cn/2020/03/18/chinese-testing-kit-exports-soaras-covid-19-spreads/

56. INNOVITA. Beijing Innotech Biotechnology Co., Ltd ._- In vitro diagnosis [Internet]. [cited 2020 Apr 9]. Available from: http://www.innovita.com. $\mathrm{cn} / \mathrm{html} / \mathrm{cn} /$

57. National Medical Products Administration. State Food and Drug Administration emergency approval of new coronavirus detection products [Internet]. [cited 2020 Apr 9]. Available from: http:// www.nmpa.gov.cn/WS04/CL2056/375802.html

58. MGI Tech. COVID-19 Total Solutions for Detection and Surveillance [Internet]. [cited 2020 Apr 
27]. Available from: https://en.mgitech.cn/resource/webinars_info/19/

59. CapitalBio RTisochip. A Isothermal Nucleic Acid Amplification Microfluidic Chip Analyzer [Internet]. [cited 2020 Apr 27]. Available from: http:// www.capitalbiotech.com/en/products-content.ht$\operatorname{ml} ? \mathrm{id}=34$

60. Cai X, Chen J, Hu J, Long Q, Deng H, Fan K, et al. A Peptide-based Magnetic Chemiluminescence Enzyme Immunoassay for Serological Diagnosis of Corona Virus Disease 2019 (COVID-19). medRxiv. 2020;

61. ID NOW COVID-19 [Internet]. [cited 2020 Mar 30]. Available from: https://www.fda.gov/media/136525/download

62. Nanjing Branch. Suzhou Medical Institute lanzó un nuevo sistema de detección rápida de ácido nucleico in situ para el coronavirus [Internet]. [cited 2020 Apr 27]. Available from: http://www.njb.cas. cn/xwdt2016/yw/202004/t20200410_5536930. html

63. ePlex ${ }^{\oplus}$ SARS-CoV-2 Test Assay Manual [Internet]. [cited 2020 Mar 30]. Available from: https://www. fda.gov/media/136282/download

64. Curti L, Pereyra-Bonnet F, Gimenez C. An ultrasensitive, rapid, and portable coronavirus SARSCoV-2 sequence detection method based on CRISPR-Cas12. bioRxiv [Internet]. 2020 Mar 2 [cited 2020 Apr 8]; Available from: https://doi. org/10.1101/2020.02.29.971127

65. ARIES - SARS-CoV-2 Assay Package Insert [Internet]. [cited 2020 Apr 8]. Available from: www. luminexcorp.com

66. Cellex qSARS-CoV-2 IgG/IgM Rapid Test [Internet]. [cited 2020 Apr 8]. Available from: https:// www.fda.gov/media/136625/download

67. QIAGEN. Sample to Insight QIAstat-Dx • Respiratory SARS-CoV-2 Panel Instructions for Use (Handbook) [Internet]. 2020 [cited 2020 Apr 5]. Available from: https://www.fda.gov/me- $\mathrm{dia} / 136571 /$ download

68. NeuMoDx Molecular. NeuMoDxTM SARS-CoV-2 Assay [Internet]. 2020 [cited 2020 Apr 5]. Available from: https://www.fda.gov/media/136565/ download

69. NxTAG ${ }^{\bullet} \mathrm{CoV}$ Extended Panel Assay Package Insert [Internet]. [cited 2020 Mar 30]. Available from: www.luminexcorp.com

70. BGI Genomics. Real-Time Fluorescent RT-PCR Kit for Detecting SARS-2019-nCoV [Internet]. 2020 [cited 2020 Mar 30]. Available from: https:// www.fda.gov/media/136472/download

71. AvellioCoV2 test EUA Summary [Internet]. [cited 2020 Mar 30]. Available from: https://www.fda. gov/media/136453/download

72. PerkinElmer. Instructions for PerkinElmer New Coronavirus Nucleic Acid Detection Kit v 1.0 [Internet]. [cited $2020 \mathrm{Mar}$ 30]. Available from: https://www.fda.gov/media/136410/download

73. Accula. SARS-CoV-2 Test [Internet]. [cited 2020 Apr 8]. Available from: https://www.fda.gov/me$\mathrm{dia} / 136355 /$ download

74. BioFire ${ }^{\bullet}$ COVID-19 Test Instructions for Use For use under an Emergency Use Authorization (EUA) only [Internet]. [cited 2020 Mar 30]. Available from: www.biofiredefense.com/covid-19test

75. Cepheid. For Use with GeneXpert Xpress System (point of care system) Xpert ${ }^{\circledR}$ Xpress SARS-CoV-2 Instructions for Use [Internet]. 2020 [cited 2020 Mar 30]. Available from: https://www.fda.gov/media/136315/download

76. Primerdesign. Genesig ${ }^{\circledR}$ Real-Time PCR assay [Internet]. 2020 [cited 2020 Mar 30]. Available from: https://www.fda.gov/media/136823/download

77. SimplexaTM COVID-19 Direct [Internet]. [cited 2020 Mar 30]. Available from: https://www.fda. gov/media/136286/download

78. Abbott RealTime SARS-CoV-2 [Internet]. [cited 2020 Mar 30]. Available from: https://www.fda. 
gov/media/136258/download

79. Quest Diagnostics. SARS-CoV-2 RNA, Qualitative Real-Time RT-PCR [Internet]. [cited 2020 Mar 30]. Available from: https://www.fda.gov/me$\mathrm{dia} / 136231 /$ download

80. Lyra SARS-CoV-2 Assay 10 Instructions for Use [Internet]. [cited 2020 Mar 30]. Available from: https://www.fda.gov/media/136227/download

81. Laboratory Corporation of America. COVID-19 RT-PCR test EUA [Internet]. [cited $2020 \mathrm{Mar}$ 30]. Available from: https://www.fda.gov/me$\mathrm{dia} / 136151 /$ download

82. Hologic. SARS-CoV-2 Assay (Panther Fusion • System) Panther Fusion ${ }^{\circledR}$ SARS-CoV-2 [Internet]. [cited 2020 Mar 30]. Available from: https://www. fda.gov/media/136156/download

83. Thermo Fisher Scientific. TaqPath TM COVID-19 Combo Kit. Multiplex real-time RT-PCR test intended for the qualitative detection of nucleic acid from SARS-CoV-2 [Internet]. [cited 2020 Mar 30]. Available from: https://www.fda.gov/me$\mathrm{dia} / 136112 /$ download

84. Cobas. SARS-CoV-2. Qualitative assay for use on the cobas ${ }^{\oplus} 6800 / 8800$ Systems [Internet]. [cited 2020 Mar 30]. Available from: https://www.fda. gov/media/136049/download

85. Wadsworth Center New York State Department of Public Health's. New York SARS-CoV-2 Real-time Reverse Transcriptase (RT)-PCR Diagnostic Panel [Internet]. [cited 2020 Mar 30]. Available from: https://www.fda.gov/media/135847/download

86. CDC 2019-Novel Coronavirus (2019-nCoV) Real-Time RT-PCR Diagnostic Panel [Internet]. [cited 2020 Mar 30]. Available from: https://www. fda.gov/media/134922/download

87. Wu Z, McGoogan JM. Characteristics of and Important Lessons from the Coronavirus Disease 2019 (COVID-19) Outbreak in China: Summary of a Report of 72314 Cases from the Chinese Center for Disease Control and Prevention. JAMA - J
Am Med Assoc. 2020;323(13):1239-1242.

88. Suo T, Liu X, Guo M, Feng J, Hu W, Yang Y, et al. ddPCR: a more sensitive and accurate tool for SARS-CoV-2 1 detection in low viral load specimens. medRxiv [Internet]. 2020 [cited $2020 \mathrm{Apr}$ 15];2020.02.29.20029439. Available from: https://doi.org/10.1101/2020.02.29.20029439

89. Bruce EA, Tighe S, Hoffman JJ, Laaguiby P, Gerrard DL, Diehl SA, et al. RT-qPCR detection of SARS-CoV-2 RNA from patient nasopharyngeal swab using Qiagen RNeasy kits or directly via omission of an RNA extraction step. bioRxiv [Internet]. 2020; Available from: https://doi. org/10.1101/2020.03.20.001008 